\title{
Pengedukasian Warga Melalui Pemberdayaan Kelompok PKK dalam Pencegahan Tindak Human Trafficking
}

\author{
Nurul Aisyah" ${ }^{1}$ \\ 1 Program StudiPendidikan Agama Islam, Fakultas Agama Isam, Universitas Muhammadiyah Yogyakarta \\ Email: nurulaisyah@umy.ac.id \\ DOI: 10.18196/ppm.34.291
}

\begin{abstract}
Abstrak
Pengabdian ini bertujuan untuk memberdayakan masyarakat padukuhan Jambusari, Wonokerto, Turi, Sleman yaitu pada kelompok PKK dalam pengedukasian pencegahan human trafficking. Hal ini didasarkan karena Yogyakarta merupakan salah satu wilayah rawan human trafficking, maka sedini mungkin desa Wonokerto Turi PKK Jambusari merasa perlu diedukasi keterkaitan agar human trafficking tidak melanda daerahnya. Metode pemberdayaan yang digunakan sehingga mencapai keefektifan yaitu melalui sosialisasi, simulasi, kampanye dan pendampingan. Target luaran telah tercapai yaitu warga PKK telah mengampanyekan kepada kelvarganya dan masyarakat bahwa berbagai dampak negatif yang didapatkan dari kegiatan terlarang ini human trafficking. Pemberdayaan ini telah dilakukan selama 3-4 bulan dengan rangkaian kegiatan yaitu 1) menyelenggarakan workshop tentang menghindari human trafficking dengan menghadirkan ahli hukum dan ahli agama; 2) menyelenggarakan dan mendampingi simulasi menolak human trafficking, sebagai langkah awal menyiapkan kader mensyiarkan ke masyarakat di Wonokerto; 3) Pemasangan berbagai pamflet penolakan human trafficking di berbagai sudut desa; 4 ) Kesiapan sebagai tim yang mewakili desa untuk lomba yang nantinya sebagai percontohan desa anti human trafficking. Pemberdayaan ini sangat dirasakan kebermanfaatannya, salah satunya menjadi awal kesiapan kelompok PKK untuk menjuarai lomba tingkat desa Wonokerto tahun ini dan menghindarkan wilayah Turi dari kejahatan aksi human trafficking.
\end{abstract}

Kata Kunci: Edukatif, Kelompok PKK, Human Trafficking

\section{Pendahuluan}

Jambusari merupakan salah satu padukuhan di Wonokerto, Turi, Sleman yang memiliki 4 RT. Padukuhan Jambusari memiliki banyak kegiatan kemasyarakatan di antaranya karang taruna untuk perkumpulan pemuda, kumpulan RT-RW untuk bapak-bapak, PAUD, Posyandu dan kumpulan PKK dan Dasawisma untuk ibu-ibu. Jambusari merupakan padukuhan aktif. Hal ini terlihat dari pertama, banyaknya kegiatan warga yang terbilang terprogram seperti dalam jangka waktu dekat akan melakukan tamanisasi di wilayah padukuhannya yang dilakukan dengan pembelian bibit dan penanaman bibit di lingkungan padukuhan melalui media tanah dan polybag. Kedua, turut serta dalam perlombaan wajib tingkat desa 2020 mendatang dengan berkompetisi dengan warga padukuhan lain khususnya dalam hal keilmuan, kekompakan dan kreatifitasannya. Ketiga, kegiatan posyandu sudah secara rutin diselenggarakan. Namun demikian berdasarkan penuturan warga di padukuhan ini, khususnya dalam hal sosial kemasyarakatan pernah terjadi penjualan anak hasil hubungan suami istri diluar pernikahan. Hal ini dibenarkan oleh ibu ketua PKK setempat, kebetulan kejadian itu terjadi di RTnya pada beberapa tahun lalu. Karena kurangnya kesadaran warga terhadap human trafficking maka tidak ada satupun warga yang melarang kegiatan jual beli tersebut. Pada saat kejadian pasangan yang bukan suami istri tersebut menyewa rumah di RT setempat, setelah beberapa bulan tanpa disadari oleh warga mereka memiliki bayi dan tidak lama kemudian yang diduga ibu sang bayi tersebut memeriksakan bayinya ke posyandu yang ada disana (Posyandu RT), dari sana kecurigaan warga mulai muncul. Ini bayi dari mana, sepengetahuan warga perempuan tersebut 
tidak pernah hamil atau sengaja menyembunyikan kehamilannya. Beberapa waktu kemudian sepasang suami istri yang diduga belum menikah tersebut ingin pindah rumah ke daerah lain. Sebelum pindah pasangan yang bukan suami istri menyerahkan bayinya kepada salah satu warga yang diduga menginginkan bayi tersebut kemudian terjadilah transaksi penyerahan bayi yang diganti (dibayar) dengan uang.

Dalam hal ini, adanya kerelaan antara keduanya atau tidak, maka hal ini tetap masuk dalam kategori perdagangan manusia yang melanggar undang-undang. Dengan adanya kejadian itu, maka perlu adanya edukasi kepada masyarakat setempat untuk mengenal lebih jauh tentang bahaya human trafficking. Berdasarkan news.detik.com (28 Agustus 2019) Daerah Istimewa Yogyakarta rawan human trafficking hal ini diungkap oleh Koentjoro selaku Ketua Dewan Guru Besar UGM bahwa pantai Gesing Gunungkidul pernah digunakan untuk jalur human trafficking ke Australia, ditambah telah ditangkapkan tersangka MY dan YK yang diduga memperdagangkan perempuan berusia belasan tahun untuk prostitusi melalui media sosial di wilayah Bantul (www.jogjatv.tv/ 2 Juni 2016) dengan harga Rp 250.000,00 hingga Rp 400.000,00 untuk sekali kencan, di mana sekitar 35\% yang diperoleh akan masuk ke kantong kedua tersangka.

Dari kasus ini YK telah dijerat dengan pasal 12 UU RI no 21 tahun 2007, tentang Perdagangan Manusia dengan hukuman penjara maksimal 15 tahun, beserta denda maksimal Rp 600 juta. Semantara tersangka MY, akan dijerat pasal 296 KUHP, pasal 10 dan pasal 11, serta UU RI no 21 tahun 2007 tentang perdagangan manusia.

Berdasarkan fakta yang ada, Yogyakarta rawan human trafficking maka sedini mungkin khususnya di Wonokerto Turi PKK Jambusari merasa perlu diedukasi keterkaitan agar human trafficking tidak melanda daerahnya. Kelompok PKK merupakan kelompok yang aktif rutinitasnya maka sasaran pengabdian ini adalah warga PKK yang tujuannya warga PKK mampu mengedukasi kepada keluarganya agar mencapai kesejahteraan keluarga dengan menghindari human trafficking. Mengingat bahwa kelompok PKK merupakan kelompok yang aktif rutinitasnya maka sasaran pengabdian ini adalah warga PKK yang mana nantinya warga PKK dapat mengampanyekan kepada keluarganya serta mengedukasi agar mencapai kesejahteraan keluarga dengan menghindari human trafficking.

Selain itu, padukuhan Jambusari merupakan satu-satunya dusun yang mendapat kesempatan untuk menampilkan simulasi dan pemahamannya terhadap kasus human trafficking dalam agenda perlombaan di desa Wonokerto. Kendala yang mereka hadapi adalah 1) tidak adanya pendampingan dari pihak yang ahli dalam keilmuan human trafficking; 2) kekompakan masih perlu ditingkatkan; 3) lemahnya pengetahuan tentang human trafficking. Dari ketiga kendala tersebut menjadi dasar utama pengabdian ini perlu dilakukan demi menuju peningkatan kesejahteraan masyarakat.

Dari data tersebut maka pentingnya dilakukan pengedukasian kepada warga terkait kesadaran dilarangnya jual beli manusia berdasarkan hukum pidana di Indonesia dan hukum Islam. Selain itu juga untuk mempersiapkan warga demi kelancaran lomba dan kesiapan diri warga keterkaitan pengetahuan tentang human trafficking.

\section{Metode Pelaksanaan}

Metode pemberdayaan yang digunakan untuk mencapai keefektifan yaitu melalui: a) sosialisasi, sosialisasi ini dilakukan pada Februari dengan mengundang pemateri membahas 
perspektif hukum dan dari perspektif agama b) simulasi, simulasi ini berupa simulasi pengedukasian kepada warga PKK sendiri maupun kepada pihak masyarakat Wonokerto; c) kampanye, kampanye ini merupakan aksi ajakan untuk menolak tindak human trafficking untuk menjaga kesejahteraan masyarakat sekitar dan d) pendampingan, pendampingan dilakukan secara intensif kepada kelompok PKK yang dilakukan dua pekan sekali.

\section{Hasil dan Pembahasan}

Pelaksanaan pemberdayaan selama 3-4 bulan ini dilaksanakan di Jambusari, Wonokerto, Turi Sleman. Pelaksanaan pemberdayaan ini adalah menyiapkan kesiapan warga PKK dalam menjuarai lomba desa Wonokerto Turi. Hal ini dapat terlihat di berbagai rangkaian kegiatan yang telah dilaksanakan selama pengabdian berlangsung, yang meliputi: 1) antusiasme warga saat berlangsungnya workshop tentang menghindari human trafficking dengan menghadirkan ahli hukum dan ahli agama (banyaknya antusiasme untuk bertanya dan berdiskusi kepada pemateri selaku ahlinya);

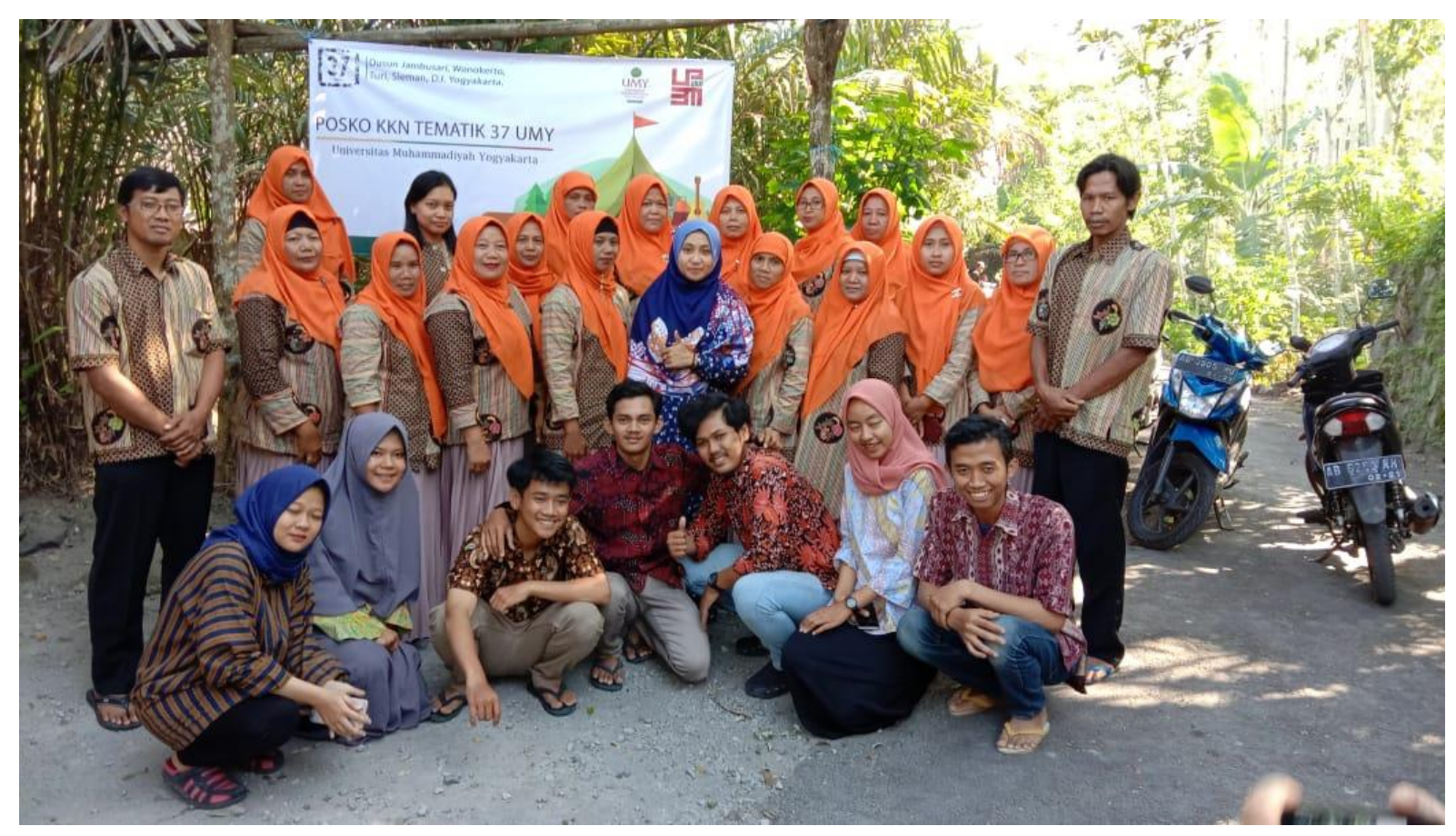

Gambar 1. Antusiasme Kelompok PKK dalam kegiatan workshop 


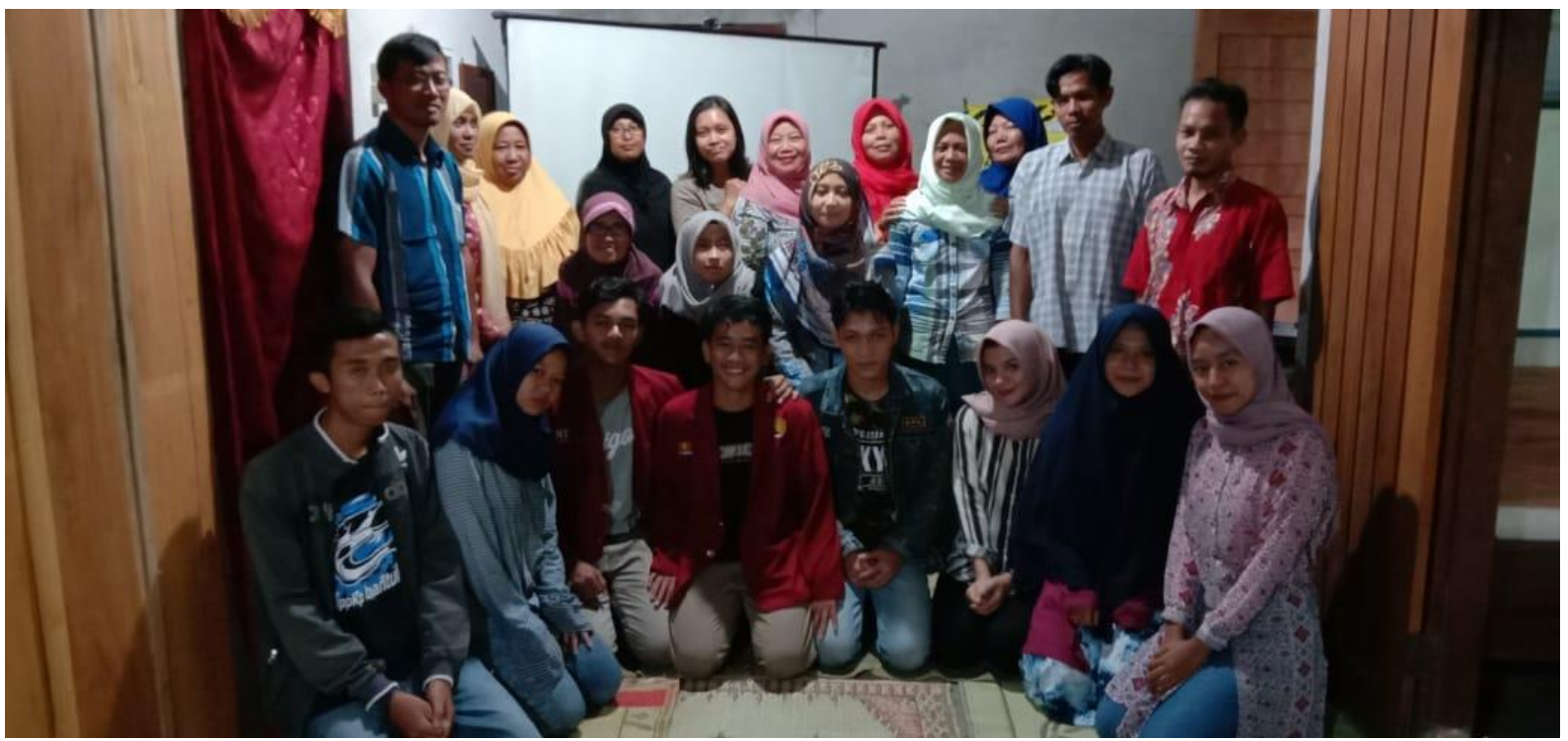

Gambar 2. Kegiatan Worshop

\begin{tabular}{|c|c|c|c|}
\hline \multicolumn{4}{|c|}{$\begin{array}{l}\text { DAFTAR HADIR PENYULUHAN HUMAN TRAFFICKING } \\
\text { OLEH KKN O37 UNIVERSITAS MUHAMMADIYAH YOGYAKARTA } \\
\text { HARI SENIN, } 13 \text { JANUARI } 2020\end{array}$} \\
\hline No & Nama & Alamat & Paraf \\
\hline 1. & Sumarni & Bangel urip & t \\
\hline 2. & Surtinah & $-1-1$ & \\
\hline 3. & Hanidinan & gondore Jo & Hrm- \\
\hline 4 & Sri Ekg M & Banyuurip & \\
\hline (5.) & Susy & Banfuupip & \\
\hline 6. & Siti sunarm & Genderejo lor & \\
\hline 7. & marjiyah & Gondorejo Cor & \\
\hline 8. & SRI Rahajuntongsih & Gondorroso kidul & Toe \\
\hline 9. & riatgiyat & isanyu-uHp & Hes: \\
\hline 10. & PUTM DK & $-6-$ & co \\
\hline II. & Suryanti & $-\cdots-$ & $\operatorname{trin}$ \\
\hline (12) & Suratinnh & Banfuurif & rasi \\
\hline 13. & Ana Nurli 5 . & 6 andoreso kidul & Onsohok \\
\hline 14. & SHI HiDaruti & conderejo lor & \\
\hline 15. & Martini & OAndorifo lor & Tims \\
\hline 16. & Ranini & Gondorej. Lor & sinp \\
\hline 17. & Haryant: & Jzonbustar & Thes \\
\hline 18. & Yatinah & jambu sar: & \\
\hline 19. & Sitiarni & ambur sar. & \\
\hline 20. & Mumarti & Jambusari & $E$ \\
\hline 21. & Win atni & Gonvorgo hor & Cmar4 \\
\hline 22. & Srilestari & Gondorgo kidul & \\
\hline 23. & Syamsigat & Gondoryjo kidue & the \\
\hline 24. & Tuk inal & $-n-$ & Fats \\
\hline
\end{tabular}

Gambar 3 Presensi kehadiran peserta workshop 


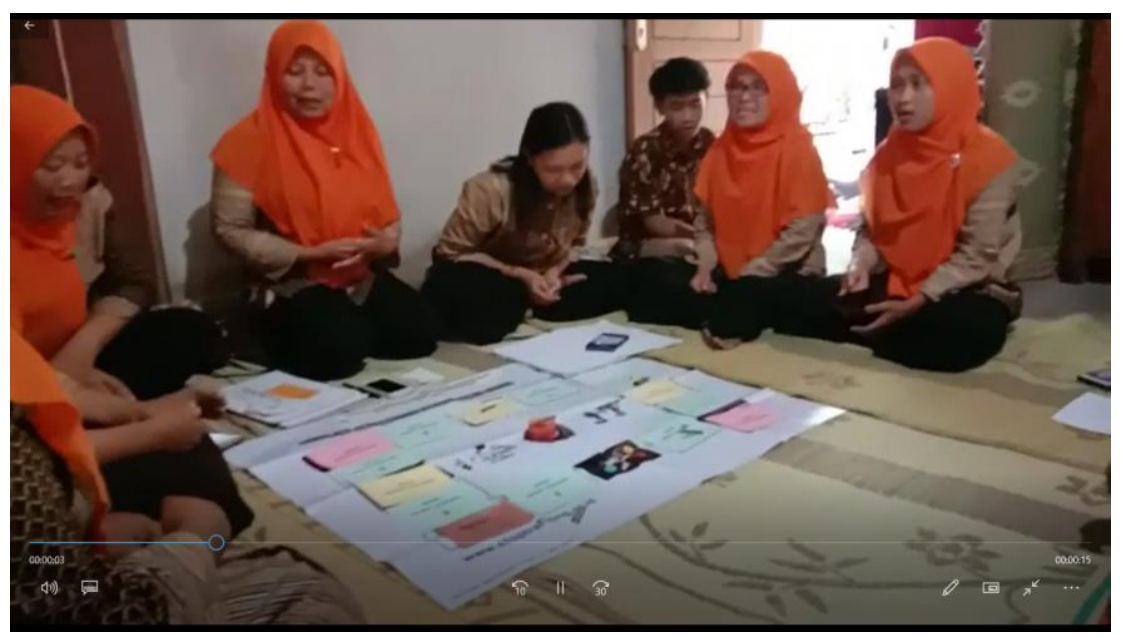

Gambar 4. Simulasi pengedukasian kepada warga Wonokerto

2) pendampingan yang selalu dihadiri oleh seluruh anggota PKK tanpa terkecuali dan komitmen mereka yang sangat tinggi, ini sebagai langkah awal menyiapkan kader menyiarkan ke masyarakat di Wonokerto; 3) telah melaksanakan aksi yang berupa pemasangan berbagai pamflet penolakan human trafficking di berbagai sudut desa; 4) Kesiapan sebagai tim yang mewakili desa untuk lomba yang nantinya sebagai percontohan desa anti human trafficking. Pengoptimalisasi kapasitas Kelompok Wanita di Desa memiliki dampak positif (Aisyah et al., 2020) dalam pengembangan Desa, salah satunya meliputi meningkatnya wawasan masyarakat terhadap pencegahan tindak pidana human trafficking di Indonesia khususnya di desa-desa.

\section{Simpulan}

Pemberdayaan pada anggota PKK sebagai kader yang mensyiarkan penolakan kejahatan human trafficking berjalan dengan baik dan effektif. Pemberdayaaan ini kebermanfaatannya sangat dirasakan oleh seluruh aspek masyarakat Wonokerto. Metode dan pendekatan yang digunakan sangat mengena di masyarakat yaitu melalui sosialisasi, simulasi, kampanye dan pendampinga. Berbagai data yang disampaikan pemberdayaan ini disimpulkan sukses dan mampu meningkatkan kemajuan desa dalam hal pengedukasian warga dari kejahatan yang mengincar.

\section{Ucapan Terima Kasih}

Ucapan terimakasih kami ucapkan kepada LP3M UMY yang menyediakan hibah pemberdayaan masyarakat ini, seluruh anggota pengabdian dan seluruh anggota PKK atas kerjasamanya.

\section{Daftar Pustaka}

Aisyah, N., Genesiska, G., \& Diwanti, D. P. (2020). Optimalisasi Kapasitas Kelompok Wanita Tani dalam Budidaya Tanaman Sayuran di Lahan Pekarangan Dusun Puluhan Lor, D.I. Yogyakarta. Jurnal Bakti Saintek: Jurnal Pengabdian Masyarakat Bidang Sains Dan

Teknologi, 4(1), 7-15. https://doi.org/10.14421/jbs.1624

news.detik.com 28 Agustus 2019

www.jogjatv.tv/ 2 Juni 2016. 